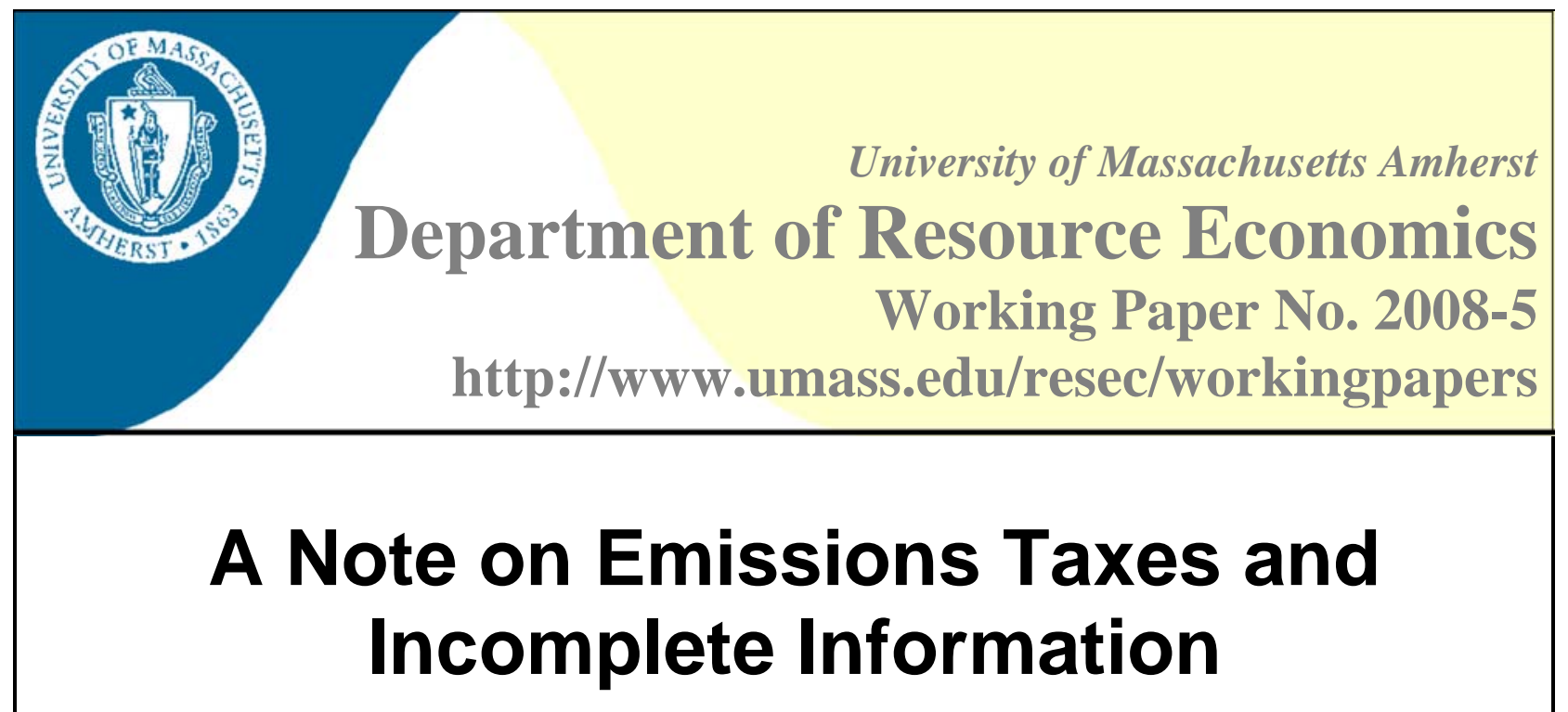

Carlos A. Chavez ${ }^{1}$ and John K. Stranlund ${ }^{2}$

Abstract:

In contrast with what we perceive is the conventional wisdom about setting emissions taxes under uncertainty, we demonstrate that setting a uniform tax equal to expected marginal damage is not generally efficient under incomplete information about firms' abatement costs and damages from pollution. We show that efficient taxes will deviate from expected marginal damage if there is uncertainty about the slopes of the marginal abatement costs of regulated firms. Moreover, efficient emissions tax rates will vary across firms if a regulator can use observable firm-level characteristics to gain some information about how the firms' marginal abatement costs vary.

Keywords: Emissions Taxes, Incomplete Information, Uncertainty

JEL Classification: L51, Q28

${ }^{1}$ Carlos A. Chavez, Departamento de Economia

Facultad de Ciencias Economicas y Administrativas

Universidad de Concepcion, Casilla (Box) 1987

Concepcion, Chili

E: cchavez@udec.cl P: 56-41-2203067 F: 56-41-2254591

${ }^{2}$ John Stranlund, Department of Resource Economics

University of Massachusetts, 214 Stockbridge Hall

80 Campus Center Way, Amherst, MA 01003-9246

E: stranlund@resecon.umass.edu P: 413-545-6328 F: 413-545-5853 


\section{A Note on Emissions Taxes and Incomplete Information}

Abstract: In contrast with what we perceive is the conventional wisdom about setting emissions taxes under uncertainty, we demonstrate that setting a uniform tax equal to expected marginal damage is not generally efficient under incomplete information about firms' abatement costs and damages from pollution. We show that efficient taxes will deviate from expected marginal damage if there is uncertainty about the slopes of the marginal abatement costs of regulated firms. Moreover, efficient emissions tax rates will vary across firms if a regulator can use observable firm-level characteristics to gain some information about how the firms' marginal abatement costs vary.

Keywords: Emissions Taxes, Incomplete Information, Uncertainty.

JEL Codes: L51, Q28.

\section{Introduction}

In a first-best world an optimal tax to control emissions of a uniformly mixed pollutant involves a uniform per unit tax set equal to marginal damage from emissions at the efficient level of aggregate emissions. It is clear that many environmental economists’ intuition about emissions taxes under incomplete information, particularly about firms' abatement costs, follows from the first-best result. That is, when we are uncertain about marginal abatement costs and perhaps marginal damage, the optimal tax is a uniform tax that is equal to expected marginal damage at the efficient expected level of aggregate emissions. The value of a uniform tax in this setting is probably the main reason for implementing price-based controls. A uniform tax leads to the distribution of emissions control that equates marginal abatement costs across sources of pollution; hence, despite the uncertainty about the level of aggregate control induced by a tax, the aggregate abatement costs of achieving the resulting level of control will be minimized.

This intuition is clearly evident in analyses of the relative efficiency of emissions taxes and competitive markets for transferable emissions quotas that began with Weitzman’s (1974) seminal work. The canonical analysis of price-based versus quantity-based emissions control 
features a tax set equal to marginal damage at expected aggregate emissions versus a competitive emissions trading program that produces a single expected permit price that is equal to marginal damage at the aggregate supply of permits. Even those that build on the difference between taxes and transferable permits under uncertainty by suggesting policies that combine price and quantity controls maintain a uniform pollution price. For example, Roberts and Spence (1976) note that one of the important consequences of their policy recommendation to combine price-based and quality-based emissions control is that individual marginal abatement costs are equal and aggregate abatement costs are minimized. Kwerel (1977) does the same. Clearly, this result holds only if emissions are controlled by a single price.

In this note we demonstrate that setting a uniform tax equal to expected marginal damage is not generally efficient under incomplete information about firms’ abatement costs and damages from pollution. The key uncertain variables are the slopes of firms' marginal abatement costs. The efficient tax on a particular firm will deviate from expected marginal damage with the variance of the slope of the firm's marginal abatement cost function, the covariance between the slope of a firm's marginal abatement cost function and marginal damage, and the covariances of the slopes of firms’ marginal abatement costs in the population of regulated firms. Moreover, efficient emissions tax rates will vary across firms if a regulator can use observable firm-level characteristics to gain some information about how the firms’ marginal abatement costs vary. In this situation, equating the marginal abatement costs of all sources of pollution is not efficient.

\section{The Basic Results}

To demonstrate these results we consider a fixed number of $n$ heterogeneous firms. These firms all emit the same uniformly mixed pollutant. Firm $i$ is described by an abatement cost function $C\left(q_{i}, x_{i}, \varepsilon_{i}\right)$, where $q_{i}$ is the firm's emissions, $x_{i}$ is a vector of characteristics of firm $i$ that a 
regulator can observe, and $\varepsilon_{i}$ is a random parameter from the regulator's perspective but it is known to the firm. A firm's abatement cost function is strictly decreasing and strictly convex in the firm's emissions. While we assume that the functional form of abatement costs does not across firms, this is not necessary for our results. Although the form of $C$ does not vary, individual firm abatement cost functions vary with differences in their observable characteristics and the realizations of the random parameter. ${ }^{1}$

Anticipating the possibility that emissions tax rates might vary across firms, let $t_{i}$ be the tax that $i$ faces. Even though the regulator does not know exactly how the firm will respond to this tax because it has only incomplete information about the firm's abatement costs, it does know that it will choose its emissions to equate its marginal abatement costs to the tax. That is,

$$
C_{q}\left(q_{i}, x_{i}, \varepsilon_{i}\right)+t_{i}=0
$$

which implicitly defines the firm's emissions as

$$
q_{i}=q\left(t_{i}, x_{i}, \varepsilon_{i}\right)
$$

Moreover, the firm's marginal response to the tax is

$$
q_{t}\left(t_{i}, x_{i}, \varepsilon_{i}\right)=-1 / C_{q q}\left(q_{i}, x_{i}, \varepsilon_{i}\right)<0
$$

Pollution damage is an imperfectly known, increasing and convex function of aggregate emissions, $D\left(\sum q_{i}, \delta\right)$, where $\delta$ is a random variable. [Unless indicated otherwise, summations are over all regulated firms]. The regulator knows the joint distribution of $\left(x_{1}, \ldots, x_{n}, \varepsilon_{1}, \ldots, \varepsilon_{n}, \delta\right)$ so it can form an expectation of the social costs of pollution and its control, conditional on its observations of $\left(x_{1}, \ldots, x_{n}\right)$. This is

\footnotetext{
${ }^{1}$ With this model we first derived the results of this section in Stranlund et al. (2008). However, we did not explore their consequences fully because we were mainly concerned with the effects of enforcement costs on optimal tax policies. In this paper we abstract away from costly enforcement to explore the affects of uncertainty on optimal emissions taxes in much more depth.
} 


$$
E\left\{\sum C\left(q_{i}, x_{i}, \varepsilon_{i}\right)+D\left(\sum q_{i}, \delta\right)\right\} .
$$

The regulator chooses individual tax rates, $\left(t_{1}, \ldots, t_{n}\right)$, to minimize [4] subject to its knowledge of how the firms will respond to their taxes, $q_{i}=q\left(t_{i}, x_{i}, \varepsilon_{i}\right), i=1, \ldots, n$. Substitute these constraints into [4] to obtain the regulator's conditional expectation of the social cost function in terms of individual emissions taxes $\left(t_{1}, \ldots, t_{n}\right)$ :

$$
E\left\{\sum C\left(q\left(t_{i}, x_{i}, \varepsilon_{i}\right), x_{i}, \varepsilon_{i}\right)+D\left(\sum q\left(t_{i}, x_{i}, \varepsilon_{i}\right), \delta\right)\right\} .
$$

Assuming that [5] is strictly convex in $\left(t_{1}, \ldots, t_{n}\right)$ and that optimality calls for a positive tax for each firm, the following first-order conditions uniquely identify the optimal tax rates:

$$
\begin{aligned}
& E\left(C_{q}\left(q_{k}\left(t_{k}, x_{k}, \varepsilon_{k}\right), x_{k}, \varepsilon_{k}\right) q_{t}\left(t_{k}, x_{k}, \varepsilon_{k}\right)\right) \\
& \quad+E\left(D^{\prime}\left(\sum q\left(t_{i}, x_{i}, \varepsilon_{i}\right), \delta\right) q_{t}\left(t_{k}, x_{k}, \varepsilon_{k}\right)\right)=0, k=1, \ldots, n .
\end{aligned}
$$

From [1] and [3], substitute $C_{q}\left(q_{k}, x_{k}, \varepsilon_{k}\right)=-t_{k}$ and $q_{t}\left(t_{k}, x_{k}, \varepsilon_{k}\right)=-1 / C_{q q}\left(q_{k}, x_{k}, \varepsilon_{k}\right), k=1, \ldots$, $n$, into [6] and rearrange the results to obtain

$$
t_{k}=\frac{E\left(D^{\prime}\left(\sum q\left(t_{i}, x_{i}, \varepsilon_{i}\right), \delta\right)\left(-1 / C_{q q}\left(q_{k}, x_{k}, \varepsilon_{k}\right)\right)\right)}{E\left(-1 / C_{q q}\left(q_{k}, x_{k}, \varepsilon_{k}\right)\right)}, k=1, \ldots, n .
$$

Finally, use the definition of the covariance between random variables to write [7] as

$$
t_{k}=E\left(D^{\prime}\left(\sum q\left(t_{i}, x_{i}, \varepsilon_{i}\right), \delta\right)\right)+\frac{\operatorname{Cov}\left(D^{\prime}\left(\sum q\left(t_{i}, x_{i}, \varepsilon_{i}\right), \delta\right),-1 / C_{q q}\left(q_{k}, x_{k}, \varepsilon_{k}\right)\right)}{E\left(-1 / C_{q q}\left(q_{k}, x_{k}, \varepsilon_{k}\right)\right)}, k=1, \ldots, n, \text { [8] }
$$

where Cov denotes the covariance operator.

The first term on the right hand side of [8] is expected marginal damage. Thus, the optimal emissions tax will be the same for every firm and will be equal to expected marginal damage if and only if the second term on the right hand side of [8] is zero. Moreover, the second 
term is zero if and only if the covariance term is zero. An important special case of this is when the slopes of the firms' marginal abatement cost functions are known. This case is important because it is common to model uncertainty about abatement costs as a random shift of only the intercept of marginal abatement costs, not their slopes. For example, in the "prices vs. quantities” literature, Weitzman (1974) focuses on this case, although not exclusively. The influential textbook treatment of this problem by Baumol and Oates (1988) takes this approach, as do many recent papers in this literature (e.g. Hoel and Karp (2002), Newell and Pizer (2003), Moledina et al. (2003), and Quirion (2004). Perhaps the intuition that an optimal tax under asymmetric information about firms' abatement costs is set equal to expected marginal damage is due, at least in part, to the common simplifying assumption that the slopes of firms' marginal abatement costs are known.

Given incomplete information about the slopes of firms’ marginal abatement costs, [8] also suggests that optimal emissions taxes will vary across firms if regulators can use observable firm characteristics to detect the variation in $E\left(-1 / C_{q q}\left(q_{k}, x_{k}, \varepsilon_{k}\right)\right), k=1, \ldots, n$. Clearly this requires that a regulator has at least some information about how observable firm characteristics affect the slopes of their marginal abatement costs. In the absence of this information it is optimal to set a uniform emissions tax, but when this information is available a uniform tax will be inefficient.

\section{The role of incomplete information in the determination of emissions taxes}

In this section we use a relatively simple example to explore the impacts of uncertain abatement costs and pollution damage on optimal individual emissions taxes. Using a specification of marginal abatement costs from Weitzman (1974 and 1978) and Laffont (1977), assume that 
information about $\left(x_{1}, \ldots, x_{n}\right)$ allows the regulator to estimate the firms' marginal abatement cost functions as

$$
-C_{q}\left(q_{i}, x_{i}, \varepsilon_{i}\right)=a_{i}+\alpha\left(\varepsilon_{i}\right)-\frac{b_{i}}{\beta\left(\varepsilon_{i}\right)} q_{i}, i=1, \ldots, n .
$$

The regulator is able to estimate the positive constants $a_{i}$ and $b_{i}$, but with errors $\alpha\left(\varepsilon_{i}\right)$ and $\beta\left(\varepsilon_{i}\right)$. Assume $E\left(\alpha\left(\varepsilon_{i}\right)\right)=0, E\left(\beta\left(\varepsilon_{i}\right)\right)=1$, and each $\alpha\left(\varepsilon_{i}\right), i=1, \ldots, n$ is independent of each $\beta\left(\varepsilon_{i}\right), i=1, \ldots, n$. Note that in this example, we can let $x_{i}=\left(a_{i}, b_{i}\right)$. Finally, suppose that marginal damage is the linear function

$$
D^{\prime}\left(\sum q\left(t_{i}, x_{i}, \varepsilon_{i}\right), \delta\right)=c+\delta+d \sum q\left(t_{i}, x_{i}, \varepsilon_{i}\right),
$$

where $c$ and $d$ are positive constants and $\delta$ is a random parameter with $E(\delta)=0 .^{2}$

For this example, equation [8] can be written as

$$
\begin{aligned}
t_{k}= & c+d \sum E\left(q\left(t_{i}, x_{i}, \varepsilon_{i}\right)\right)+d E\left(q\left(t_{k}, x_{k}, \varepsilon_{k}\right)\right) \operatorname{Var}\left(\beta\left(\varepsilon_{k}\right)\right) \\
& +d \sum_{i \neq k} E\left(q\left(t_{i}, x_{i}, \varepsilon_{i}\right)\right) \operatorname{Cov}\left(\beta\left(\varepsilon_{i}\right), \beta\left(\varepsilon_{k}\right)\right)+\operatorname{Cov}\left(\delta, \beta\left(\varepsilon_{k}\right)\right) . \quad k=1, \ldots, n,
\end{aligned}
$$

where $\operatorname{Var}\left(\beta\left(\varepsilon_{k}\right)\right)$ is the variance of $\beta\left(\varepsilon_{k}\right)$. (The derivation of equation [11] is available upon request). < For review purposes only we have attached it as a reviewer's appendix $>$ Note that the first two terms on the right side of [11] is the regulator's expectation of marginal damage, given individual taxes $\left(t_{1}, \ldots, t_{n}\right)$ and its estimates of the abatement cost parameters $\left(a_{i}, b_{i}\right), i=1, \ldots, n$. As we noted in section 2 , an optimal policy is to set a single tax equal to expected marginal damage if the slopes of all the marginal abatement cost functions are known, because in this case all the variance and covariance terms in [11] are equal to zero.

\footnotetext{
${ }^{2}$ Our primary reason for choosing this specification of the problem is that it produces a linear decomposition of the influences of uncertainty on efficient emissions taxes.
} 
To further explore how randomness in the slopes of firms' marginal abatement cost functions affects the relationship between their optimal emission taxes and expected marginal damage, note that the third term on the right hand side of [11] involves the marginal damage associated with the firms' emissions times the variance of the random factor of the slopes of their marginal abatement cost functions. This term is clearly positive when marginal damage is increasing, which indicates that its impact on a particular firm $k$ 's tax rate is to push it above expected marginal damage. Furthermore, the optimal tax rate increases as the regulator's uncertainty about $\beta\left(\varepsilon_{k}\right)$ increases. Recall that the reciprocal of the slope of a firm's marginal abatement cost function measures the emissions response of the firm to a marginal increase in its tax. Thus, the greater the regulator's uncertainty about a firm's marginal response to an emissions tax, the higher is its optimal tax. This effect also depends on the convexity of the damage function. For example, it is zero if marginal damage is a constant (i.e., $d=0$ ). However, a more steeply sloped marginal damage function implies that each firms' tax rate exceeds expected marginal damage by a greater amount.

For a particular firm $k$, the fourth term on the right hand side of [11] involves the marginal damage associated with all the other firms' emissions times the covariances of the random factor of the slopes of their marginal abatement costs curves with the random factor of the slope of $k$ 's marginal abatement cost curve. Of course, if the $\beta\left(\varepsilon_{i}\right)$ 's are independently distributed this term is equal to zero; however, if they are not independently distributed it seems reasonable to assume that they would often vary together. In that case, the third term on the right hand side of [11] is positive, and the impact of this term on $k$ 's tax rate is to push it further above expected marginal damage. This effect is again enhanced when the marginal damage function is steeper. 
Finally, the fifth term on the right hand side of [11] reflects how marginal damage and the slope of $k$ 's marginal abatement cost curve vary together. We don't have an a priori expectation of how $\delta$ and $\beta\left(\varepsilon_{k}\right)$ might vary together if at all. Let us note, however, that if $\delta$ and $\beta\left(\varepsilon_{k}\right)$ are independent of each other, $\operatorname{Cov}\left(\delta, \beta\left(\varepsilon_{k}\right)\right)=0$. However, if marginal damage is positively (negatively) correlated with the slopes of marginal abatement costs, then $\operatorname{Cov}\left(\delta, \beta\left(\varepsilon_{k}\right)\right)<(>) 0$, which implies a reduction (increase) in $k$ 's tax rate.

Besides indicating that optimal tax rates will likely vary from expected marginal damage, [11] also indicates that tax rates will vary across firms as well. To explore this, let us simplify the problem by assuming that the $\beta\left(\varepsilon_{i}\right)$ 's are identically, but not necessarily independently, distributed. In this case, $\operatorname{Var}\left(\beta\left(\varepsilon_{i}\right)\right)$ and $\operatorname{Cov}\left(\delta, \beta\left(\varepsilon_{i}\right)\right)$ are the same for each $i$, and $\operatorname{Cov}\left(\beta\left(\varepsilon_{i}\right), \beta\left(\varepsilon_{k}\right)\right)$ is the same for every pair of firms $i$ and $k$. Then, using [11] we can calculate the difference between the tax rates for firms $k$ and $i$ as:

$$
t_{k}-t_{i}=d\left[\sigma_{\beta}^{2}-\operatorname{Cov}_{\beta}\right]\left[E\left(q\left(t_{k}, x_{k}, \varepsilon_{k}\right)\right)-E\left(q\left(t_{i}, x_{i}, \varepsilon_{i}\right)\right)\right],
$$

where $\sigma_{\beta}^{2}$ denotes the variance of each $\beta\left(\varepsilon_{i}\right)$ and $\operatorname{Cov}_{\beta}$ denotes the covariance between any $\beta\left(\varepsilon_{k}\right)$ and $\beta\left(\varepsilon_{i}\right)$. Note that individual tax rates will not vary in our example if marginal damage is constant (i.e., $d=0$ ), which we've already mentioned; if the variance and covariance terms are equal, which is highly unlikely, or if under the optimal policy the regulator's conditional expectations of the firms' emissions are the same. On this last point, in this example $E\left(q\left(t_{i}, x_{i}, \varepsilon_{i}\right)\right)=\left(a_{i}-t_{i} / b_{i}\right), i=1, \ldots, n$. Then, $t_{k}-t_{i}=d\left[\sigma_{\beta}^{2}-\operatorname{Cov}_{\beta}\right]\left[\left(a_{k}-t_{k}\right) / b_{k}-\left(a_{i}-t_{i}\right) / b_{i}\right]$ Therefore, given $d \neq 0$ and $\sigma_{\beta}^{2} \neq \operatorname{Cov}_{\beta}$, the optimal policy is a uniform tax $t$ if and only if $\left(a_{k}-t / b_{k}\right)=\left(a_{i}-t / b_{i}\right)$ for each pair of firms $i$ and $k$. This is exceedingly unlikely, except when 
a regulator has such poor information about individual firms that it cannot distinguish its estimates of the intercepts and slopes of their marginal abatement costs from one another.

\section{Conclusion}

We have demonstrated that uncertainty about the slopes of firms’ marginal abatement costs implies that optimal emissions taxes to control a uniformly mixed pollutant will generally differ from expected marginal damage. Moreover, this uncertainty leads to a policy of differentiated taxes, except when regulators do not have any knowledge of the variation of marginal abatement costs in the population of regulated firms. The extent of the deviations of optimal tax rates from expected marginal damage and whether they should vary across firms are empirical matters that should be addressed in each pollution control setting. 


\section{References}

Baumol, William J. and Wallace E. Oates. 1988. The Theory of Environmental Policy, Cambridge University Press.

Hoel, Michael and Larry Karp. 2002. “Taxes versus quotas for a stock pollutant.” Resource and Energy Economics 24(4) 367-384.

Kwerel, Evan. 1977. “To tell the truth: Imperfect information and optimal pollution control.” The Review of Economic Studies 44 (3), 595-601.

Laffont, Jean Jacques. 1977. "More on prices vs. quantities.” Review of Economic Studies 44(1), 177-182.

Moledina, Amyaz A.; Jay S. Coggins, Stephen Polasky and Christopher Costello. 2003. "Dynamic environmental policy with strategic firms: Prices versus quantities." Journal of Environmental Economics and Management 45(2S), 356-376.

Newell, Richard G., and William A. Pizer. 2003. "Regulating stock externalities under uncertainty." Journal of Environmental Economics and Management 45 (2, Supplement 1), 416-432.

Quirion, Phillippe. 2004. "Prices versus quantities in a second-best setting.” Environmental \& Resource Economics 29(3): 337-359.

Roberts, M.J. and M. Spence. 1976. "Effluent charges and licenses under uncertainty," Journal of Public Economics 5, 193-208.

Stranlund, John K.; Carlos A. Chavez, and Mauricio Villena. 2008. "The optimal pricing of pollution when enforcement is costly." Unpublished manuscript.

Weitzman, Martin L. 1974. "Prices vs. quantities." Review of Economic Studies 41(4), 477-91.

Weitzman, Martin. 1978. "Reply to "Prices vs. quantities: A critical note on the use of approximations” by James M. Malcomson.” Review of Economic Studies 45(1), 209-210. 


\section{Reviewers’ Appendix: The Derivations of Equation [11]}

A firm $i$ 's choice of emissions given a tax $t_{i}$ is the solution to $-C_{q}\left(q_{i}, x_{i}, \varepsilon_{i}\right)=t_{i}$. With [9], solving for i's emissions yields:

$$
q\left(t_{i}, x_{i}, \varepsilon_{i}\right)=\frac{\left(a_{i}+\alpha\left(\varepsilon_{i}\right)-t_{i}\right) \beta\left(\varepsilon_{i}\right)}{b_{i}},
$$

with expectation

$$
E\left(q\left(t_{i}, x_{i}, \varepsilon_{i}\right)\right)=\frac{\left(a_{i}-t_{i}\right)}{b_{i}}
$$

Moreover, the firm's marginal response to a change in the tax is

$$
q_{t}\left(t_{i}, x_{i}, \varepsilon_{i}\right)=-\beta\left(\varepsilon_{i}\right) / b_{i},
$$

with expectation

$$
E\left(q_{t}\left(t_{i}, x_{i}, \varepsilon_{i}\right)\right)=-1 / b_{i} \text {. }
$$

Substitute [A3] into equation [7] to write firm $k$ 's optimal tax as

$$
t_{k}=\frac{E\left(D^{\prime}\left(\sum q\left(t_{i}, x_{i}, \varepsilon_{i}\right), \delta\right)\left(-\beta\left(\varepsilon_{k}\right) / b_{k}\right)\right)}{-1 / b_{k}}=E\left(D^{\prime}\left(\sum q\left(t_{i}, x_{i}, \varepsilon_{i}\right), \delta\right) \cdot \beta\left(\varepsilon_{k}\right)\right)
$$

Substitute $D^{\prime}\left(\sum q\left(t_{i}, x_{i}, \varepsilon_{i}\right), \delta\right)=c+\delta+d \sum q\left(t_{i}, x_{i}, \varepsilon_{i}\right)$ (equation [10] in the text) and [A1] into [A5] to obtain

$$
t_{k}=E\left(c \beta\left(\varepsilon_{k}\right)+\delta \beta\left(\varepsilon_{k}\right)\right)+d \sum \frac{\left(a_{i}-t_{i}\right) E\left(\beta\left(\varepsilon_{i}\right) \beta\left(\varepsilon_{k}\right)+E\left(\alpha\left(\varepsilon_{i}\right) \beta\left(\varepsilon_{i}\right) \beta\left(\varepsilon_{k}\right)\right)\right.}{b_{i}}
$$

Since each $\alpha\left(\varepsilon_{i}\right), i=1, \ldots, n$, is independent of each $\beta\left(\varepsilon_{i}\right), i=1, \ldots, n$, and $E\left(\alpha\left(\varepsilon_{i}\right)\right)=0$, $E\left(\alpha\left(\varepsilon_{i}\right) \beta\left(\varepsilon_{i}\right) \beta\left(\varepsilon_{k}\right)\right)=0$. Moreover, since $E\left(\beta\left(\varepsilon_{k}\right)\right)=1$, and $c$ is a constant, $E\left(c \beta\left(\varepsilon_{k}\right)+\delta \beta\left(\varepsilon_{k}\right)\right)=c+E\left(\delta \beta\left(\varepsilon_{k}\right)\right)$. Finally, from [A2], $E\left(q\left(t_{i}, x_{i}, \varepsilon_{i}\right)\right)=\left(a_{i}-t_{i}\right) / b_{i}$. Therefore, [A6] can be written as

$$
t_{k}=c+d \sum E\left(q\left(t_{i}, x_{i}, \varepsilon_{i}\right)\right) E\left(\beta\left(\varepsilon_{i}\right) \beta\left(\varepsilon_{k}\right)\right)+E\left(\delta \beta\left(\varepsilon_{k}\right)\right) .
$$

Using the definition of covariance:

$$
E\left(\beta\left(\varepsilon_{i}\right) \beta\left(\varepsilon_{k}\right)\right)=\operatorname{Cov}\left(\beta\left(\varepsilon_{i}\right)_{i}, \beta\left(\varepsilon_{k}\right)\right)+E\left(\beta\left(\varepsilon_{i}\right)\right) E\left(\beta\left(\varepsilon_{k}\right)\right)=\operatorname{Cov}\left(\beta\left(\varepsilon_{i}\right), \beta\left(\varepsilon_{k}\right)\right)+1,
$$

and 


$$
E\left(\delta \beta\left(\varepsilon_{k}\right)\right)=\operatorname{Cov}\left(\delta, \beta\left(\varepsilon_{k}\right)\right)+E(\delta) E\left(\beta\left(\varepsilon_{k}\right)\right)=\operatorname{Cov}\left(\delta, \beta\left(\varepsilon_{k}\right)\right) .
$$

Substitute [A8] and [A9] into [A7] to obtain

$$
t_{k}=c+d \sum E\left(q\left(t_{i}, x_{i}, \varepsilon_{i}\right)\right)\left(\operatorname{Cov}\left(\beta\left(\varepsilon_{i}\right), \beta\left(\varepsilon_{k}\right)\right)+1\right)+\operatorname{Cov}\left(\delta, \beta\left(\varepsilon_{k}\right)\right) .
$$

Again from the definition of covariance, $\operatorname{Cov}\left(\beta\left(\varepsilon_{k}\right), \beta\left(\varepsilon_{k}\right)\right)=\operatorname{Var}\left(\beta\left(\varepsilon_{k}\right)\right)$, where $\operatorname{Var}\left(\beta\left(\varepsilon_{k}\right)\right)$ is the variance of $\beta\left(\varepsilon_{k}\right)$. Using this, [A10] can be written as

$$
\begin{aligned}
t_{k}= & c+d \sum E\left(q\left(t_{i}, x_{i}, \varepsilon_{i}\right)\right)+d E\left(q\left(t_{k}, x_{k}, \varepsilon_{k}\right)\right) \operatorname{Var}\left(\beta\left(\varepsilon_{k}\right)\right) \\
& +d \sum_{i \neq k} E\left(q\left(t_{i}, x_{i}, \varepsilon_{i}\right)\right) \operatorname{Cov}\left(\beta\left(\varepsilon_{i}\right), \beta\left(\varepsilon_{k}\right)\right)+\operatorname{Cov}\left(\delta, \beta\left(\varepsilon_{k}\right)\right),
\end{aligned}
$$

which is equation [11]. 